\title{
Seroprevalence of Syphilis among a Cohort of HIV-infected Subjects in North Central Nigeria
}

Sir,

The first case of HIV in Nigeria was reported in 1986 in a sexually-active 13 years old girl, and soon afterwards, HIV infection was identified among commercial sex workers in Lagos and Enugu. Cases of HIV infection were occasionally reported from various parts of the country and have been growing steadily (1). Now, Nigeria has the largest HIV/AIDS epidemic in sub-Sahara Africa (2). A syphilis-prevalence rate of $4.1 \%$ and $4 \%$ was reported among commercial sex workers in Ibadan and Lagos respectively $(3,4)$. A syphilis-seroprevalence rate of $0.125 \%, 1.7 \%$, and $2.97 \%$ was also reported among pregnant women in Enugu, Ilorin, and Oshogbo respectively (5-7).

Insufficient information on the prevalence of HIV-syphilis co-infection in Nigeria is available. Nnoruka and Ezeoke attempted to fill this gap by reporting a $2.1 \%$ prevalence rate of HIV-syphilis co-infection in a hospital setting in Enugu state of Nigeria (8). Their study did not look at the influence of such a concurrent HIV-syphilis infection on the immune system, which is critical in the proper management of this group of patients. As far as we know, no study in northern Nigeria (HIV/ AIDS hotspot) has looked at this phenomenon. To begin to address this public-health problem in this very vast country (over 148 million inhabitants in an area of 923,768 sq km), we conducted a study on the prevalence of HIV-syphilis co-infection and the possible effect of such co-infection on the $\mathrm{CD}^{+}$ lymphocyte levels among HIV-infected individuals in North Central Nigeria.

Four hundred plasma samples were randomly selected from western blot-confirmed HIV 1-positive samples stored at $-24^{\circ} \mathrm{C}$ in the Virology Laboratory of Innovative Biotech (IBL), Keffi, Nasarawa state,

Correspondence and reprint requests should be addressed to:

Dr. Joseph C. Forbi

Virology Laboratory

Innovative Biotech-Keffi/Abuja

1 Abdu Abubakar Street

GRA Keffi, Nasarawa State

Nigeria

Email: cforbi79@hotmail.com
Nigeria. These samples were collected during June 2005-December 2007 from clients who accessed IBL services for voluntary HIV counselling and testing or for other health needs. Before each client was bled, informed consent was obtained according to the IBL and international regulations. These samples were labelled with serialized IBL code numbers that could not be linked to individuals. As patients were bled, a superior fluorescence-activated cellsorter system (Becton Dickenson FACSCount, Canada) was used for enumerating the absolute values for $\mathrm{CD}^{+}$cells for each sample according to the instructions of the manufacturer. The $\mathrm{CD} 4^{+} / \mathrm{CD}^{+}$ ratios were also enumerated using the FACSCount method in a closed tube format.

Anti-Treponema palladium (the spirochete that causes syphilis) antibodies (IgG and $\operatorname{IgM}$ ) were detected in plasma using the Shantest ${ }^{\mathrm{TM}}$ syphilis test-kit [(Shantha Biotechnics Ltd., Hyderabad, India; Lot number: 5151101; sensitivity 99.7\% (98.6$100 \%)$; specificity $99.6 \%$ (98.5-100\%)] which use a double antigen combination of a recombinant syphilis antigen-coated particle and syphilis antigen immobilized on membrane to detect $T$. palladium antibodies (IgG and IgM) qualitatively and selectively in plasma. The test was carried out and interpreted according to the instructions of the manufacturer.

Demographic data (age and gender) of the participants were retrieved from the coded electronic registration records of clients maintained at the IBL. The seroprevalence of HIV and syphilis and median were obtained after recording data in a Microsoft Excel worksheet on a Windows 98 platform. The IBL research committee and the ethical committee of the Nasarawa State University approved the study.

Of the 400 samples tested, 263 were from females and 137 from males. Thirteen individuals were positive for both HIV and syphilis. The prevalence of HIV-syphilis co-infection was 3.3\%. Of the 13 individuals co-exposed to HIV and syphilis, five were female while eight were male. More males were HIV-syphilis co-exposed but this was not significant. The age range of the study patients was 15-67 years (mean 32 years). The mean age of HIV-syphi- 
lis co-infected females was 30.4 years against 46.3 years for males. There was no age preference for HIV-syphilis co-infection. The prevalence of HIVsyphilis among females was 1.9\% (5/263) and 5.8\% $(8 / 137)$ among males. The ratio between males and females with HIV-syphilis co-infection was approximately 1.6:1. The median $\mathrm{CD} 4^{+}$value of HIV-syphilis co-infected individual was 27 cells/ $\mu \mathrm{L}$ (range 1453 cells $/ \mu \mathrm{L}$ ) while that for those with only HIV infection was 169 cells/ $\mu \mathrm{L}$ (range 1-980 cells $/ \mu \mathrm{L}$ ). The $\mathrm{CD}^{+}$values in HIV-syphilis co-infection were usually over three times greater than $\mathrm{CD}^{+}$values. This was, however, not too different from an observation in HIV mono-infected individuals.

Since HIV and syphilis are both sexually transmissible infections, their association in the same individual is not unusual. HIV infection may alter primary manifestations of syphilis, leading to an atypical presentation and/or multiple ulcers that may be mistaken for genital herpes. Lesions fitting the classic descriptions of painless, solitary ulcers with indurations only occur in $31 \%$ of patients with syphilis (9). As many as one in three HIV-infected people continue to have unprotected sex after knowing that they are HIV-positive, and unprotected sex often occurs with unknown sero-status or HIV-negative individual (10). The samples used in this study were collected from Nasarawa state and Abuja. This axis is a known HIV/AIDS hotspot (1).

The present study estimated the prevalence of HIV-syphilis co-infection rate of $3.3 \%$ among HIVinfected individuals. This is in agreement with Nnoruka and Ezeoke (8) who reported 2.1\% prevalence rate of HIV-syphilis co-infection in Enugu state of Nigeria. Results of several epidemiological studies showed that the prevalence of syphilis in Nigeria ranged from $0.125 \%$ to $4.1 \%$ among pregnant women and commercial sex workers (3-7). It is likely that the prevalence of syphilis in Nigeria could be in the same range regardless of occupation in different segments of the Nigerian population. The rate of syphilis infection in Nigeria is lower compared to other countries in the West-African subregion. For example, the syphilis-seroprevalence rate of $11 \%, 20 \%$, and $23.8 \%$ has been reported in Ghana, Sierra Leone, and Senegal respectively (11-13). The unofficially-unrestricted sales of drug in buses, streets, and markets in Nigeria result in an extensive use of antibiotics, especially ampicillins which can stop syphilis. This could result in a low and inefficient transmission of T. palladium, leading to the eventual decrease in the number of seropositive individuals over time. The low preva- lence of syphilis among HIV-infected individuals in the present study and other studies from Nigeria suggests that elimination of syphilis is possible in Nigeria if preventive and control measures are put in place.

The ratio between males and females with HIVsyphilis co-infection was approximately 1.6:1. Therefore, HIV-infected men are 1.6 times more likely to be syphilis-positive than HIV-infected women. This is in line with the Rio de Janeiro study where a larger number of men than women were co-infected with HIV and syphilis (14). We did not find an association between the prevalence of HIVsyphilis co-infection and age. This is perhaps due to the increasing and widespread distribution of HIV infection in all age-categories in Nigeria.

In this study, the median $\mathrm{CD} 4^{+}$counts was lower among individuals co-exposed to HIV/syphilis (median $\mathrm{CD}^{+}=27$ cells $/ \mu \mathrm{L}$ ) when compared with individuals having HIV mono-infection (median $\mathrm{CD}^{+}=169$ cells $/ \mu \mathrm{L}$ ). Although our study is limited by the fact that we cannot clearly state if the syphilis infection we detected was active or prior, we think that our observation perhaps corroborates the observation of Sadiq et al. and Palacios et $a l$. who found a drop in the $\mathrm{CD} 4^{+}$count among individuals with HIV/syphilis co-infection in the United Kingdom and Spain respectively $(15,16)$. Furthermore, Kofoed et al., in Copenhagen, Denmark, demonstrated that treatment of syphilis was associated with an increase in the $\mathrm{CD} 4^{+}$cell count (17). The combination of HIV and syphilis is a dangerous one and provides further challenges to HIV-control programmes, particularly in countries in sub-Saharan Africa that have a high prevalence of HIV infection.

Although the seroprevalence of syphilis among HIV-infected individuals is low in Nigeria, we recommend a nation-wide integration of screening and treatment of syphilis in the overall management of HIV infection because of the potentiallydevastating effect of this dual infection on the immune system. This has been shown to have some benefits in countries where the practice is adopted.

\section{REFERENCES}

1. Nigeria. Federal Ministry of Health. Technical report: 2003 national HIV sero prevalence sentinel survey. Abuja: National AIDS/STDs Control Programme, Department of Public Health, Federal Ministry of Health, Government of Nigeria 2004. 94 p.

2. United Nations Programme on HIV/AIDS. Report on 
the global HIV/AIDS epidemic. Sub-Saharan Africa AIDS epidemic update regional summary 2007. Geneva: Joint United Nations Programme on HIV/AIDS, 2007. 18 p. (http://data.unaids.org/pub/Report/2008/ JC1526_epibriefs_subsaharanafrica_en.pdf, accessed on 30 April 2009).

3. Bakare RA, Oni AA, Umar US, Adewole IF, Shokunbi WA, Fayemiwo SA et al. Pattern of sexually transmitted diseases among commercial sex workers (CSWs) in Ibadan, Nigeria. Afr J Med Med Sci 2002;31:243-7.

4. Dada AJ, Ajayi AO, Diamondstone L, Quinn TC, Blattner WA, Biggar RJ. A serosurvey of Haemophilus ducreyi, syphilis, and herpes simplex virus type 2 and their association with human immunodeficiency virus among female sex workers in Lagos, Nigeria. Sex Transm Dis 1998;25:237-42.

5. Taiwo SS, Adesiji YO, Adekanle DA. Screening for syphilis during pregnancy in Nigeria: a practice that must continue. Sex Transm Infect 2007;83:357-8.

6. Ikeme AC, Okeke TC. The relevance of VDRL as routine test in pregnant women: a critcal study. Niger $J$ Clin Pract 2006;9:65-7.

7. Aboyeji AP, Nwabuisi CJ. Prevalence of sexually transmitted diseases among pregnant women in Ilorin, Nigeria. J Obstet Gynaecol 2003;23:637-9.

8. Nnoruka EN, Ezeoke AC. Evaluation of syphilis in patients with HIV infection in Nigeria. Trop Med Int Health 2005;10:58-64.

9. DiCarlo RP, Martin DH. The clinical diagnosis of genital ulcer disease in men. Clin Infect Dis 1997;25:2928.

10. Marks G, Burris S, Peterman TA. Reducing sexual transmission of HIV from those who know they are infected: the need for personal and collective responsibility. AIDS 1999;13:297-306.

11. Adjei AA, Armah HB, Gbagbo F, Ampofo WK, Quaye IK,
Hesse IF et al. Prevalence of human immunodeficiency virus, hepatitis $B$ virus, hepatitis $C$ virus and syphilis among prison inmates and officers at Nsawam and Accra, Ghana. J Med Microbiol 2006;55(Pt 5):593-7.

12. Ronday MJ, Stilma JS, Barbe RF, McElroy WJ, Luyendijk L, Kolk AH et al. Aetiology of uveitis in Sierra Leone, West Africa. Br J Ophthalmol 1996;80:956-61.

13. Laurent C, Seck K, Coumba N, Kane T, Samb N, Wade A et al. Prevalence of HIV and other sexually transmitted infections, and risk behaviours in unregistered sex workers in Dakar, Senegal. AIDS 2003;17:1811-6.

14. Signorini DJ, Monteiro MC, de Sá CA, Sion FS, Leitão Neto HG, Lima DP et al. Prevalence of HIV-syphilis coinfection in a university hospital in the city of Rio de Janeiro in 2005. Rev Soc Bras Med Trop 2007;40:282-5.

15. Sadiq ST, McSorley J, Copas AJ, Bennett J, Edwards SJ, Kaye S et al. The effects of early syphilis on CD4 counts and HIV-1 RNA viral loads in blood and semen. Sex Transm Infect 2005;81:380-5.

16. Palacios R, Jiménez-Oñate F, Aguilar M, Galindo MJ, Rivas P, Ocampo A et al. Impact of syphilis infection on HIV viral load and CD4 cell counts in HIV-infected patients. J Acquir Immune Defic Syndr 2007;44:356-9.

17. Kofoed K, Gerstoft J, Mathiesen LR, Benfield T. Syphilis and human immunodeficiency virus (HIV)-1 coinfection: influence on CD4 T-cell count, HIV-1 viral load, and treatment response. Sex Transm Dis 2006;33:143-8.

\section{Forbi Joseph ${ }^{1,2}$, Pennap Grace 2 , Obinyelaku Arthur', Iperepolu Odunayo', and Agwale Simon'}

'Virology Laboratory, Innovative Biotech-Keffi/Abuja, I, Abdu

Abubakar Street, GRA Keffi, Nasarawa State, Nigeria and ${ }^{2}$ Department of Microbiology, Nasarawa State University, Keffi, Nasarawa State, Nigeria 